\title{
Comparison of Absorbable Packing versus No Packing in Wound Healing after Endoscopic Sinus Surgery: A Systematic Review and Pooled Analysis
}

\author{
Zhenxiao Huang Bing Zhou \\ Department of Otolaryngology, Head and Neck Surgery, Beijing Tongren Hospital, Capital Medical University, \\ Beijing, PR China
}

\section{Keywords}

Absorbable $\cdot$ Packing $\cdot$ Endoscopic sinus surgery $\cdot$ Wound healing $\cdot$ Pooled analysis

\begin{abstract}
Introduction: Nasal packing after endoscopic sinus surgery (ESS) is controversial. The aim of this systematic review was to compare absorbable packing versus no packing in wound healing after ESS for the treatment of chronic rhinosinusitis. Data Source: English electronic databases, including Cochrane Library, EMBASE, MEDLINE, and PubMed, were searched, and only randomized controlled trials were included. Methods: The outcome measures were the presence of synechiae/adhesion formation, mucosal edema, crusting, granulation formation, and infection. The McNemar's test was used for pooled analysis. Results: Four studies with 148 participants were included. The pooled analysis showed that absorbable packing may offer benefit in reducing adhesion at $6-8$ weeks (odds ratio [OR]: $0.3864 ; 95 \%$ confidence interval [Cl]: $0.2136-0.7235)$ and 12 weeks (OR: $0.2396,95 \% \mathrm{Cl}$ : 0.08267-0.7709) postoperatively compared with no packing. There was no significant difference between the packed and the unpacked side at 2, 6-8, and 12 weeks after ESS in terms of presence of crusting, edema, and granulation formation. Conclusion: There is insufficient evidence to sug-
\end{abstract}

gest that absorbable packing after ESS does not increase mucosal edema, granulation formation, and infection. However, the absorbable packing may be more effective than no packing for the prevention of mucosal adhesion after ESS. The use of absorbable nasal packing after ESS is recommended when used to reduce postoperative mucosal adhesion. More research in this area is clearly needed.

(c) 2021 S. Karger AG, Basel

\section{Introduction}

Absorbable nasal packing materials are commonly used after endoscopic sinus surgery (ESS) [1]. The International Consensus Statement on Allergy and Rhinology: rhinosinusitis recommended that nasal packing does not appear to be necessary in the majority of ESS cases [1]. If nasal packing is chosen, the existing evidence indicates that nasal packing achieves hemostasis without significant adverse effects on postoperative wound healing $[2,3]$.

Surgical outcomes are often compromised by postoperative abnormal wound healing issues, such as adhesion. Optimal mucosal wound healing is critical for good surgical outcomes [1]. Multiple clinical randomized controlled trials (RCTs) have investigated the effects of different absorbable packing materials on wound healing, included 
adhesion formation, mucosal edema, crusting, and inflammation. An RCT conducted by Valentine et al. [3] showed that chitosan-dextran (CD) gel could significant lower the rate of adhesion formation in the first 3 months postoperatively compared with no packing. Conversely, another RCT conducted by Wormald et al. [4] found the opposite results, showing that postoperative nasal packing did not offer additional effects for promoting wound heal compared with no packing. Hence, we performed a systematic review (SR) and pooled analysis of RTCs that evaluated the use or not of absorbable nasal packing material after ESS. The principal outcome evaluated was the postoperative mucosal wound healing.

\section{Patients and Methods}

\section{Search Methods}

The Cochrane Library, EMBASE, MEDLINE, and PubMed were systematically searched from their inception to January 1, 2020. There were no language, publication year, or publication status restrictions. The search strategies are presented in online suppl. material 1; see www.karger.com/doi/10.1159/000514793 for all online suppl. material.

\section{Selection Criteria}

Two review authors independently screened the studies, and any discrepancy was resolved by discussion. The inclusion criteria were as follows: (1) adult patients (age equal to or greater than 18 years old) diagnosed with chronic rhinosinusitis with nasal polyps or without nasal polyps (CRSsNP) according to the definition from the latest 2018 Chinese CRS guideline or the EPOS201214; (2) RCT study design; (3) comparisons included absorbable packing versus no packing; (4) use of intrapatient control design; and (5) published in English. Exclusion criteria (1) nonrandomized and quasirandomized trials; (2) RCTs with no clear description of randomization methods or those only assessing cost-effectiveness of relevant interventions; and (3) RCTs using interpatient comparisons.

\section{Outcome Measures}

The primary outcome for this pooled study was endoscopic grading scales at 2 weeks and 12 weeks postoperatively. This scoring system included adhesion, mucosal edema, crusting, granulation tissue, and evidence of infection [2-5].

\section{Risk of Bias}

The risk of bias was assessed by both authors for all the included RCTs based on the standard criteria outlined by the Cochrane Collaboration [6]. For any disagreement, a consensus was reached through discussion.

Data Extraction and Management

The 2 authors independently performed data extraction using a standardized data form. Each review author would review approximately the same number of studies. We planned to refer unresolved disagreements on inclusion, "risk of bias" assessment and data collection to 2 authors. Data to be extracted included the following:

Absorbable Packing in ESS

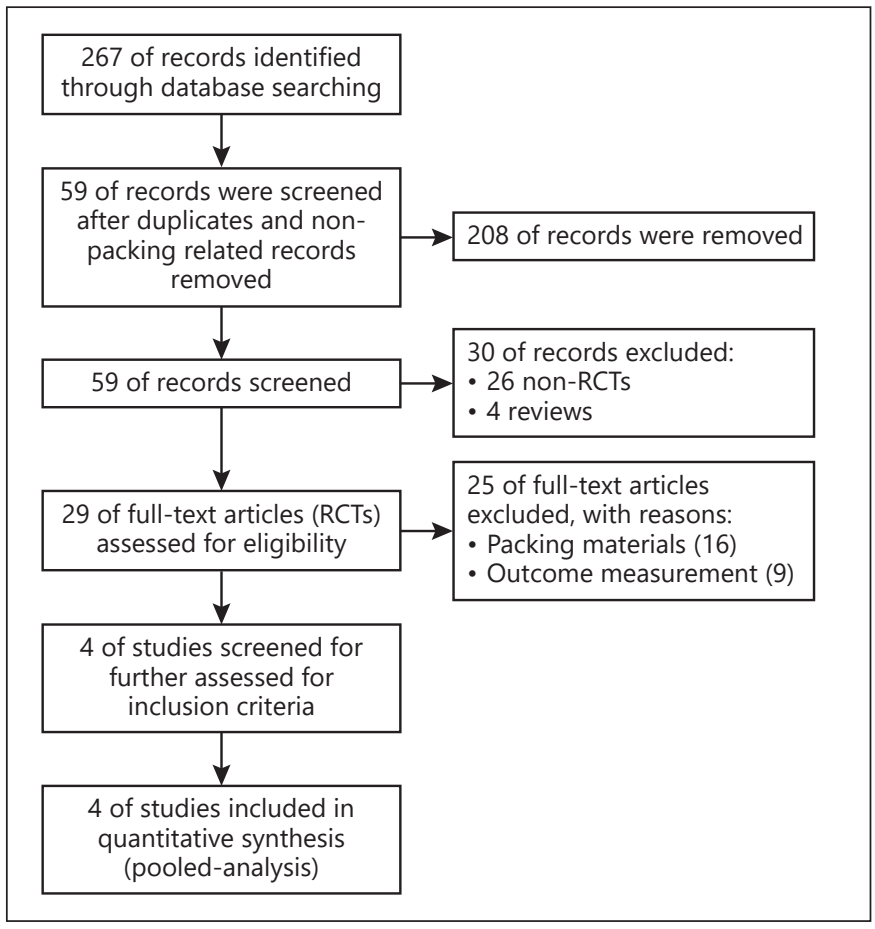

Fig. 1. Flow diagram of the study.

- study design;

- study eligibility criteria;

- methodology;

- information on methods for "Risk of bias" assessment;

- outcome/measurements.

- follow-up; and

- conclusions.

\section{Statistical Analysis}

Statistical analysis was performed using GraphPad Prism 8.0 software (La Jolla, CA, USA). The analysis for all endpoints was conducted using the McNemar's test on a $2 \times 2$ classification table, arising from the intrapatient control design, in which patients serve as their own control. All $p$ values are 2 -sided, and any $p$ value $<0.05$ was considered statistically significant. Two previous studies also used the McNemar's test for the pooled analysis of effect of steroid-releasing sinus stent on ESS $[7,8]$. The heterogeneity and "risk of bias" assessment were analyzed by Review Manager Version 5.3 software (The Cochrane Collaboration, Oxford, UK).

\section{Results}

\section{Search Results}

The initial search retrieved 267 citations for possible inclusion. After removing duplicated citations or citations not related to nasal packing, 59 publications were identified. Thirty papers were excluded after abstract re- 
Table 1. The characteristics of included studies $(N=148)$

\begin{tabular}{|c|c|c|c|c|}
\hline Patients' characteristic & RCT 1 & RCT 2 & RCT 3 & RCT 4 \\
\hline Institution & Multiple & Single & Multiple & Multiple \\
\hline Year & 2013 & 2011 & 2010 & 2006 \\
\hline Study design & Randomized, single blinded & $\begin{array}{l}\text { Randomized, double } \\
\text { blinded }\end{array}$ & Randomized, blinded & $\begin{array}{l}\text { Randomized, } \\
\text { single blinded }\end{array}$ \\
\hline Sample size & 26 patients, 52 sides & 40 patients, 80 sides & 40 patients, 80 sides & $\begin{array}{l}42 \text { patients, } 84 \\
\text { sides }\end{array}$ \\
\hline Age, mean & 48.6 & 48.2 & 49.5 & \\
\hline $\begin{array}{l}\text { Absorbable packing material } \\
\text { versus no packing }\end{array}$ & CD gel & $\begin{array}{l}\text { Microporous } \\
\text { polysaccharide } \\
\text { hemospheres }\end{array}$ & CD gel & Hyaluronic acid \\
\hline Follow-up & 2,8 , and 12 weeks & 1,2 , and 4 weeks & 2,6 , and 12 weeks & $\begin{array}{l}2,4 \text {, and } 6-8 \\
\text { weeks }\end{array}$ \\
\hline
\end{tabular}

RCT, randomized controlled trial; CD, chitosan-dextran.

vision. 29 full-text articles were reviewed for eligibility, after this revision 25 studies were excluded. Finally, 4 RCTs with 148 participants were included in the pooled analysis (Fig. 1; Table 1) [2-5]. The sample size of each included study ranged from 26 to 42 patients.

\section{Interventions and Included Studies}

The 4 RCTs investigated the use of various absorbable packing materials (Table 1) [2-5]. These materials included hyaluronic acid (Merogel; Medtronic Xomed, Jacksonville, FL, USA), CD gel, and microporous polysaccharide hemospheres (MPH; commercially available as Arista; Medafor, Inc., Minneapolis, MN, USA). All of these materials are biodegradable and intended to promote either wound healing or intraoperative and postoperative hemostasis.

\section{Excluded Studies}

Twenty-five studies were excluded given that did not meet the inclusion criteria [9-33].

\section{Data Management}

We collected the ordinal data from the 4 RCTs included. These ordinal data (ordinate scores: 0,1 , and 2 or 0,1 , 2 , and 3 ) were converted into binary data (0: not present and 1: present).

\section{Risk of Bias Assessment}

Figure 2 shows the risk of bias assessment for all included studies. "Low risk" is shown in green, "unclear risk" is shown in yellow, and "high risk" is shown in red.

\section{Wound Healing at 2 Weeks Postoperatively}

\section{Adhesion Formation}

Four studies compared the use of nasal absorbable packing versus no packing in reducing adhesion formation evaluated 2 weeks after ESS [2-5]. There was no significant difference between the nasal absorbable packing side and the unpacked side in terms of mucosal adhesion formation after ESS ( $p=0.1167$, odds ratio [OR]: 0.5785, 95\% confidence interval [CI]: 0.3172-1.103).

\section{Mucosal Edema}

Four studies compared the use of nasal absorbable packing versus no packing in reducing mucosal edema evaluated 2 weeks after ESS [2-5]. There was no significant difference between the nasal absorbable packing side and the unpacked side in terms of presence of mucosal edema after ESS ( $p=0.8153$, OR: 0.9213, 95\% CI: 0.57781.466). 


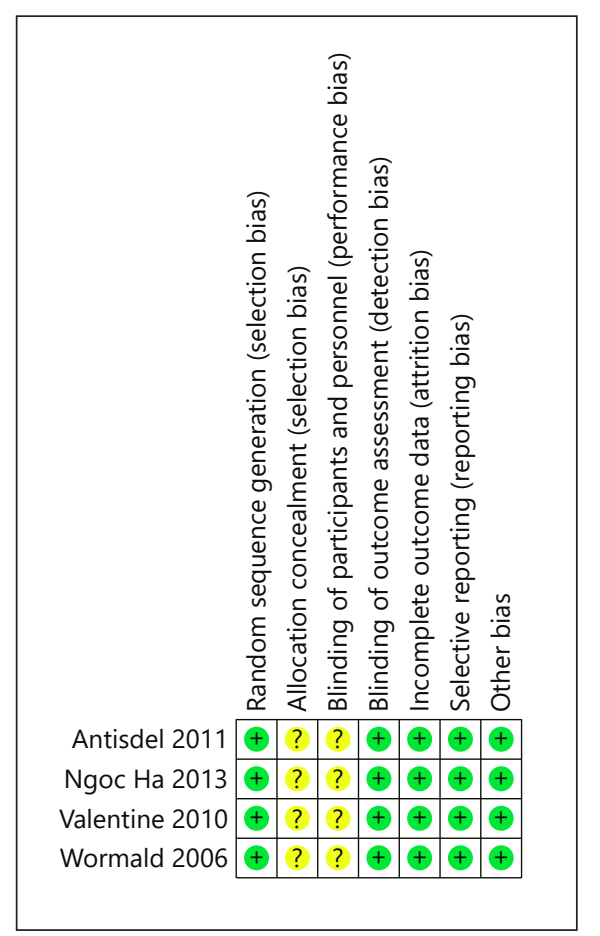

Fig. 2. Risk of bias summary.

\section{Crusting and Granulation Formation}

Two studies compared the use of nasal absorbable packing versus no packing in reducing crusting and granulation formation 2 weeks after ESS $[3,5]$. There was no significant difference between the nasal absorbable packing side and the unpacked side in terms of the presence of mucosal crusting and granulation tissue formation after ESS ( $p=0.584$, OR: 0.7653, 95\% CI: 0.3861-1.597; $p$ > 0.999, OR: 1, 95\%: 0.5109-1.957).

\section{Infection}

Three studies compared the use of nasal absorbable packing versus no packing in the incidence of infection in 2 weeks after ESS [2-4]. There was no significant difference between the nasal absorbable packing side and the unpacked side in terms of the presence of postoperative infection after ESS ( $p=0.66$, OR: $1.118,0.7063-$ 1.774).

\section{Wound Healing at 6-8 Weeks Postoperatively}

\section{Adhesion Formation}

Three studies compared the use of nasal absorbable packing versus no packing in reducing adhesion forma-

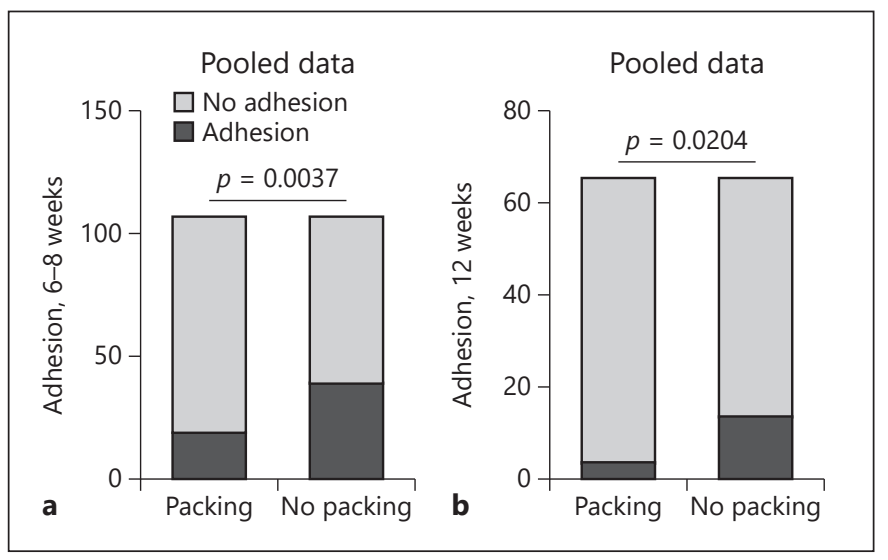

Fig. 3. Mucosal adhesion at 6-8 weeks and 12 weeks postoperatively.

tion at 6-8 weeks after ESS [3-5]. The percentage of mucosal adhesion in the packed side was significantly decreased compared with the unpacked side $(p=0.0037$, OR: $0.3864,95 \%$ CI: $0.2136-0.7235$ ) (Fig. 3). No statistical heterogeneity was found among studies $\left(\chi^{2}=5.12, \mathrm{df}=2\right.$ $\left.(p=0.08) ; I^{2}=61 \%\right)$.

\section{Mucosal Edema}

Three studies compared the use of nasal absorbable packing versus no packing in edema, crusting, and granulation formation at 6-8 weeks after ESS [3-5]. There was no significant difference between packed and unpacked sides in terms of the presence of mucosal edema at 6-8 weeks after ESS ( $p=0.3367$, OR: 0.7394, 95\% CI: $0.4322-$ 1.253).

\section{Wound Healing at 12 Weeks Postoperatively}

\section{Adhesion Formation}

Two studies compared the use of nasal absorbable packing versus no packing in reducing adhesion at 12 weeks after ESS (Table 2) $[3,5]$. The percentage of mucosal adhesion in the absorbable packing side was significantly decreased compared with the unpacked side ( $p=$ 0.0204, OR: 0.2396, 95\% CI: 0.08267-0.7709) (Table 2; Fig. 3,4$)$. No statistical heterogeneity was found among the studies $\left(\chi^{2}=2.57, \mathrm{df}=1,=0.11, I^{2}=61 \%\right)$.

\section{Mucosal Edema, Crusting, and Granulation}

Two studies compared the use of nasal absorbable packing versus no packing in edema, crusting, and granulation formation 12 weeks after ESS (Table 2) [3, 5]. There 
Fig. 4. Forest plots of endoscopic outcomes at 12 weeks.

\begin{tabular}{|c|c|c|c|c|}
\hline \multicolumn{5}{|c|}{ Endoscopic outcomes at 12 weeks (Ngoc Ha 2013 and Valentine 2010) } \\
\hline & & & OR $95 \% \mathrm{Cl}$ & $p$ value \\
\hline Granulation & $\longmapsto$ & $\longrightarrow$ & $1(0.39-2.58)$ & $>0.9999$ \\
\hline Crusting & $\longmapsto$ & $\longrightarrow$ & $0.86(0.32-2.63)$ & $>0.9999$ \\
\hline Edema & $\longmapsto$ & & $0.72(0.33-1.65)$ & 0.54 \\
\hline \multirow[t]{3}{*}{ Adhesion } & $\longmapsto \vdash$ & & $0.24(0.78-0.08)$ & 0.02 \\
\hline & 0 & $\begin{array}{l}1 \\
2\end{array}$ & 3 & \\
\hline & Favor treatment & Favor control & & \\
\hline
\end{tabular}

Table 2. Endoscopic outcomes at 12 weeks: adhesion, edema, crusting, and granulation

\begin{tabular}{|c|c|c|c|c|c|c|}
\hline \multirow[t]{2}{*}{ Outcomes } & \multicolumn{2}{|c|}{ RCT 1 (Ngoc Ha et al. [5]) } & \multicolumn{2}{|c|}{ RCT 3 (Valentine et al. [3]) } & \multicolumn{2}{|c|}{ Pooled analysis } \\
\hline & $\begin{array}{l}\text { packing } \\
(N=26)\end{array}$ & $\begin{array}{l}\text { no packing } \\
(N=26)\end{array}$ & $\begin{array}{l}\text { packing } \\
(N=40)\end{array}$ & $\begin{array}{l}\text { no packing } \\
(N=40)\end{array}$ & $\begin{array}{l}\text { packing } \\
(N=66)\end{array}$ & $\begin{array}{l}\text { no packing } \\
(N=66)\end{array}$ \\
\hline \multicolumn{7}{|l|}{ Adhesion } \\
\hline Evaluable, $n$ & 26 & 26 & 40 & 40 & 66 & 66 \\
\hline$N(\%)$ & $2(7.69)$ & $2(7.69)$ & $2(5)$ & $12(30)$ & $4(6.06)$ & $14(21.21)$ \\
\hline$p$ value & $>0.9999$ & & 0.0064 & & 0.0204 & \\
\hline \multicolumn{7}{|l|}{ Edema } \\
\hline Evaluable, $n$ & 26 & 26 & 40 & 40 & 66 & 66 \\
\hline$N(\%)$ & $6(23.07)$ & $9(34.6)$ & $8(20)$ & $11(27.5)$ & $14(21.2)$ & $18(27.27)$ \\
\hline$p$ value & 0.5414 & & 0.6001 & & 0.5428 & \\
\hline \multicolumn{7}{|l|}{ Crusting } \\
\hline Evaluable, $n$ & 26 & 26 & 40 & 40 & 66 & 66 \\
\hline$N(\%)$ & $0(0)$ & $1(3.84)$ & $7(27.5)$ & $7(27.5)$ & $7(10.6)$ & $8(12.12)$ \\
\hline$p$ value & $>0.9999$ & & $>0.9999$ & & $>0.9999$ & \\
\hline \multicolumn{7}{|l|}{ Granulation } \\
\hline Evaluable, $n$ & 26 & 26 & 40 & 40 & 66 & 66 \\
\hline$N(\%)$ & $2(7.69)$ & $5(19.23)$ & $7(17.5)$ & $4(10)$ & $9(13.6)$ & $9(13.6)$ \\
\hline$p$ value & 0.4189 & & 0.5179 & & $>0.9999$ & \\
\hline
\end{tabular}

was no significant difference between the use of nasal absorbable packing and no packing in terms of the presence of mucosal edema, adhesion, and granulation after ESS ( $p=0.5428$, OR: $0.7179,95 \%$ CI: $0.3258-1.648 ; p>0.9999$, OR: $0.8602,95 \%$ : 0.3223-2.632; $p>0.9999$, OR: $1,95 \%$ CI: $0.3886-2.573)$.

\section{Discussion}

\section{Summary of Main Results}

There are a variety of reasons to use nasal packing after ESS, including to contribute to wound healing and to en- hance intraoperative and postoperative hemostasis. The aim of this study was to assess the efficacy of absorbable packing material in contributing to wound healing after ESS. The endoscopic grading scale system is widely used for evaluating the severity of wound healing after ESS.

In our review, we identified 4 RCTs that met our eligibility criteria [2-5]. Ngoc Ha et al. [5] and Valentine et al. [3] were prospective, randomized, controlled studies. The authors used a within-patient control design, comparing the absorbable packing material CD gel to no packing. This study showed that $\mathrm{CD}$ gel produced significantly less stenosis of all neo-ostia following ESS compared with no packing in patients with CRS. Antisdel et al. [2] conduct- 
ed a prospective, randomized, double-blind controlled study that included 40 CRS patients. The authors also used a within-patient control design, comparing the use of absorbable packing material MPH versus no packing. This study showed that MPH was associated with decreased postoperative bleeding without an apparent adverse effect on healing when compared with no packing [2]. However, a multicenter RCT showed that Merogel nasal packing did not offer additional significant beneficial or detrimental effects in terms of adhesion, edema, or infection when placed in the middle meatus after ESS. Hence, it was difficult to reach a conclusion about the efficacy of absorbable nasal packing in reducing wound healing after ESS based on the eligible evidence. Our SR and pooled analysis addressed these questions by systematically collecting relevant RCTs and pooling their results when applicable.

Our pooled analysis found that the use of absorbable packing failed to confer beneficial effects in reducing adhesion, edema, granulation tissue, and crusting formation at 2 weeks postoperatively compared with no packing. However, the use of absorbable packing may offer beneficial effects on reducing adhesion, but not edema, granulation, and crusting formation at 6-8 and 12 weeks postoperatively compared with no packing. Our results indicated that absorbable packing might contribute to wound healing at later stages after ESS.

\section{Quality of the Evidence}

Blinding was poorly reported by the studies included, which could lead to potential bias. The sample size of the RCTs included was small. Fortunately, all 4 studies adopted intrapatient comparison. In this setting, the sample size was doubled and sufficient for statistical analysis. The long-term outcomes data (greater than 12 weeks) was insufficient and needs to be investigated in future studies.

\section{Potential Biases in the Review Process}

The strength of this systemic review is the comprehensive literature search, including several databases and clinical trial registers. We only included studies published in English, which may cause a language bias. We had 2 independent authors screen the studies and extract data to reduce systematic error.

\section{Agreements and Disagreements with Other Studies or \\ Reviews}

We identified 1 similar SR and meta-analysis [34] on this subject. The authors undertook a SR to determine the effectiveness of middle meatus packing material for the prevention of synechiae following ESS. The authors found that the use of middle meatus packing materials may be more effective than no packing for the prevention of synechiae following ESS, especially when employing nonabsorbable packing. However, the authors failed to address the wound healing issues, such as granulation formation and edema, etc. The goal of our SR was to perform a pooled analysis of the effect of absorbable packing in contributing to postoperative wound healing, included mucosal edema, granulation formation, and infection.

Currently, there are 2 SRs and pooled analyses that aimed to investigate the effects of steroid-eluting sinus stent for CRS patients who had undergone ESS [7, 34]. These pooled analyses revealed a beneficial impact on postoperative healing. These 2 SRs used pooled analysis (McNemar's test), which uses a $2 \times 2$ classification table, arising from the intrapatient control design. Our current SRs also used pooled analysis (McNemar's test) for the analysis of the data from RCTs. Interestingly, our previous Cochran SR and meta-analysis that aimed to investigate the effects of steroid-eluting sinus stent for CRS patients who had undergone ESS [35]. Our previous study identified 2 relevant RCTs. However, we excluded these 2 RCTs because of they used the intrapatient control design.

\section{Conclusion}

We found insufficient evidence to suggest that the use of absorbable packing after ESS does not increase mucosal edema, granulation formation, and infection. However, the use of absorbable packing may be more effective than the use of no packing for the prevention of mucosal adhesion after ESS. The use of absorbable nasal packing after ESS is recommended to reduce postoperative mucosal adhesion. Clearly more research in this area is needed.

\section{Acknowledgement}

We thank Dr. Nathalia Velasquez, Department of Otolaryngology - Head and Neck Surgery, University of Pittsburgh Medical Center for reviewing and editing the manuscript.

\section{Statement of Ethics}

Our study was conducted ethically in accordance with the World Medical Association Declaration of Helsinki. The paper is exempt from Ethical Committee approval owing to this study is a SR of published literature. 


\section{Conflict of Interest Statement}

The authors have no financial relationships or conflicts of interest to disclose.
(DFL20150202) program and the priming scientific research foundation for junior researcher (2016-YJJ-BJRC-003) Clinical Medicine Development of Special Funding Support in Beijing Tongren Hospital, Capital Medical University (No. trzdyxy201702).

\section{Funding Sources}

This study was supported by grants from the National Natural Science Foundation of China (No. 81271063 and 81500770), Beijing Municipal Administration of Hospitals' "Dengfeng"

\section{Author Contributions}

Zhenxiao Huang: designed the study, screened the citations, performed the analysis, and wrote the manuscript. Bing Zhou: designed the study, screened the citations, and reviewed the manuscript.

\section{References}

1 Orlandi RR, Kingdom TT, Hwang PH, Smith TL, Alt JA, Baroody FM, et al. International consensus statement on allergy and rhinology: rhinosinusitis. Int Forum Allergy Rhinol. 2016;6(S1):S22-S209.

2 Antisdel JL, Matijasec JL, Ting JY, Sindwani R. Microporous polysaccharide hemospheres do not increase synechiae after sinus surgery: randomized controlled study. Am J Rhinol Allergy. 2011;25(4): 268-71.

3 Valentine R, Athanasiadis T, Moratti S, Hanton L, Robinson S, Wormald PJ. The efficacy of a novel chitosan gel on hemostasis and wound healing after endoscopic sinus surgery. Am J Rhinol Allergy. 2010; 24(1):70-5

4 Wormald PJ, Boustred RN, Le T, Hawke L, Sacks R. A prospective single-blind randomized controlled study of use of hyaluronic acid nasal packs in patients after endoscopic sinus surgery. Am J Rhinol. 2006; 20(1):7-10.

5 Ngoc Ha T, Valentine R, Moratti S, Robinson S, Hanton L, Wormald PJ. A blinded randomized controlled trial evaluating the efficacy of chitosan gel on ostial stenosis following endoscopic sinus surgery. Int Forum Allergy Rhinol. 2013;3(7):573-80.

6 Higgins JPT, Green S. Cochrane handbook for systematic reviews of interventions. Version 5.1.0. Updated March 2011. London, UK: The Cochrane Collaboration; 2011. Available from: https://trainingcochraneorg/handbook. Accessed 2019 January 3 .

7 Han JK, Marple BF, Smith TL, Murr AH, Lanier BJ, Stambaugh JW, et al. Effect of steroidreleasing sinus implants on postoperativemedical and surgical interventions: an efficacy meta-analysis. Int Forum Allergy Rhinol. 2012;2(4):271-9.

8 Singh A, Luong AU, Fong KJ, Ow RA, Han JK, Gerencer R, et al. Bioabsorbable steroidreleasing implants in the frontal sinus ostia: a pooled analysis. Int Forum Allergy Rhinol. 2019;9(2):131-9.
9 Shinkwin CA, Beasley N, Simo R, Rushton L, Jones NS. Evaluation of surgicel Nu-knit, merocel and vasolene gauze nasal packs: a randomized trial. Rhinology. 1996;34(1): 41-3.

10 Frenkiel S, Desrosiers MY, Nachtigal D. Use of hylan B gel as a wound dressing after endoscopic sinus surgery. J Otolaryngol. 2002;31(Suppl 1):S41-4.

11 Kimmelman CP, Edelstein DR, Cheng HJ. Sepragel sinus (hylan B) as a postsurgical dressing for endoscopic sinus surgery. Otolaryngol Head Neck Surg. 2001;125:603-8.

12 Chandra RK, Conley DB, Haines GK3rd, Kern RC. Long-term effects of FloSeal packing after endoscopic sinus surgery. Am J Rhinol. 2005;19(3):240-3.

13 Miller RS, Steward DL, Tami TA, Sillars MJ, Seiden AM, Shete M, et al. The clinical effects of hyaluronic acid ester nasal dressing (Merogel) on intranasal wound healing after functional endoscopic sinus surgery. Otolaryngol Head Neck Surg. 2003;128(6): 862-9.

14 Jameson M, Gross CW, Kountakis SE. FloSeal use in endoscopic sinus surgery: effect on postoperative bleeding and synechiae formation. Am J Otolaryngol. 2006; 27(2):86-90.

15 Bugten V, Nordgård S, Skogvoll E, Steinsvåg $S$. Effects of nonabsorbable packing in middle meatus after sinus surgery. Laryngoscope. 2010;116(1):83-8.

16 Franklin JH, Wright ED. Randomized, controlled, study of absorbable nasal packing on outcomes of surgical treatment of rhinosinusitis with polyposis. Am J Rhinol, 2007;21:214-7.

17 Antisdel JL, West-Denning JL, Sindwani R. Effect of microporous polysaccharide hemospheres (MPH) on bleeding after endoscopic sinus surgery: ran- domized controlled study. Otolaryngol Head Neck Surg. 2009; 141:353-7.
18 Shoman N, Gheriani H, Flamer D, Javer A Prospective, double-blind, randomized trial evaluating patient satisfaction, bleeding, and wound healing using biodegradable synthetic polyurethane foam (NasoPore) as a middle meatal spacer in functional endoscopic sinus surgery. J Otolaryngol Head Neck Surg. 2009;38(1):112-8.

19 Berlucchi M, Castelnuovo P, Vincenzi A, Morra B, Pasquini E. Endoscopic outcomes of resorbable nasal packing after functional endoscopic sinus surgery: a multicenter prospective randomized controlled study. Eur Arch Otorhinolaryngol. 2009;266(6): 839-45.

20 Kastl KG, Betz CS, Siedek V, Leunig A. Effect of carboxymethylcellulose nasal packing on wound healing after functional endoscopic sinus surgery. Am J Rhinol Allergy. $2009 ; 23(1): 80-4$.

21 Szczygielski K, Rapiejko P, Wojdas A, Jurkiewicz D. Use of CMC foam sinus dressing in FESS. Eur Arch Otorhinolaryngol. 2010;267(6):537.

22 Beyea JA, Rotenberg BW. Comparison of purified plant polysaccharide (HemoStase) versus gelatin-thrombin matrix (FloSeal) in controlling bleeding during sinus surgery: a randomized controlled trial. Ann Otol Rhinol Laryngol. 2011;120(8):495-8.

23 Kim DW, Lee EJ, Kim SW, Jeon SY. Advantages of glove finger-coated polyvinyl acetate pack in endoscopic sinus surgery. Am J Rhinol Allergy. 2012;26(6):e147-9.

24 Akbari E, Philpott CM, Ostry AJ, Clark A, Javer AR. A double-blind randomised controlled trial of gloved versus ungloved merocel middle meatal spacers for endoscopic sinus surgery. Rhinology. 2012; 50(3):306-10. 0

25 Cho KS, Shin SK, Lee JH, Kim JY, Koo SK, Kim YW, et al. The efficacy of Cutanplast nasal packing after endoscopic sinus surgery: a prospective, randomized, controlled trial. Laryngoscope. 2013;123(3):564-8.

26 Mo JH, Park YM, Chung YJ. Effect of lidocaine-soaked nasal packing on pain relief after endoscopic sinus surgery. Am J Rhinol Allergy. 2013;27:e174-7. 
27 Shi R, Zhou J, Wang B, Wu Q, Shen Y, Wang $P$, et al. The clinical outcomes of new hyaluronan nasal dressing: a prospective, randomized, controlled study. Am J Rhinol Allergy. 2013;27(1):71-6.

28 Al-Shaikh S, Muddaiah A, Lee RJ, Bhutta MF. Oxidised cellulose powder for haemostasis following sinus surgery: a pilot randomised trial. J Laryngol Otol. 2014;128(8): 709-13.

29 Verim A, Seneldir L, Naiboğlu B, Karaca ÇT, Külekçi S, Toros SZ, et al. Role of nasal packing in surgical outcome for chronic rhinosinusitis with polyposis. Laryngoscope. 2014;124(7):1529-35.
30 Yu MS, Kang SH, Kim BH, Lim DJ. Effect of aerosolized fibrin sealant on hemostasis and wound healing after endoscopic sinus surgery: a prospective randomized study. Am J Rhinol Allergy. 2014;28(4):335-40.

31 Akiyama K, Karaki M, Yonezaki M, Goto $\mathrm{R}$, Inamoto R, Hoshikawa $\mathrm{H}$, et al. Usefulness of nasal packing with silver-containing carboxy methylated cellulose in endonasal sinus surgery. Auris Nasus Larynx. 2014;41(3):264-8.

32 Kastl KG, Reichert M, Scheithauer MO, Sommer F, Kisser U, Braun T, et al. Patient comfort following FESS and Nasopore packing, a double blind, prospective, randomized trial. Rhinology. 2014;52(1):605 .
33 Vaiman M, Sarfaty S, Shlamkovich N, Segal S, Eviatar E. Fibrin sealant: alternative to nasal packing in endonasal operations. A prospective randomized study. Isr Med Assoc J. 2005;7(9):571-4.

34 Lee JM, Grewal A. Middle meatal spacers for the prevention of synechiae following endoscopic sinus surgery: a systematic review and meta-analysis of randomized controlled trials. Int Forum Allergy Rhinol. 2012;2:477-86.

35 Huang Z, Hwang P, Sun Y, Zhou B. Steroid-eluting sinus stents for improving symptoms in chronic rhinosinusitis patients undergoing functional endoscopic sinus surgery. Cochrane Database Syst Rev. 2015;6:CD010436. 